\title{
Some interactions in a higher order multiple schedule of reinforcement*
}

\author{
ROGER SCHNAITTER \\ Ilinois Weslevan University, Bloomington, $\mathrm{Il} .61701$ \\ and

STEPHEN WINOKUR
Texan Christian University. Fort Worth. Tex. 76129

Two pigeons were trained on a multiple schedule, of which each component was a chain schedule. A high-rate contingency was added to one component of one chain. Negative behavioral contrast was observed. Tests for emotionality were negative. Reinforcement rates were constant and equal in both chains throughout the experiment.

Reynolds (1961) had claimed that the relative temporal densities of reinforcement in each of two components of a multiple schedule of reinforcement are the causes of behavioral contrast. However, Terrace (1966) has argued that if the rate of responding in the presence of one component is reduced, behavioral contrast will occur. Exceptions to this rule occur when the discriminations are established without producing emotional by-products (Terrace, 1972). In order to explore the adequacy of these views, it is necessary to manipulate response rates in a multiple schedule independently of changes in reinforcement rates. Two types of experiments appear to be relevant in this context. One type employs a multiple schedule with a VI component and a DRL component. The other type of experiment uses a multiple schedule with VI and DRH components. In both kinds of experiments, reinforcement rates are to be kept constant in both components of the schedule before and after the introduction of the DRL or DRH contingencies.

Experiments where response rates in one component of a multiple schedule were lowered by using DRL schedules have been reported, but such work has been subjected to severe methodological criticism (Dunham, 1968; Freeman, 1971), and thus is ambiguous. Experiments using a constant rate of reinforcement and a DRH component do not appear to have been reported. An experiment using a higher order multiple schedule with a superimposed DRH contingency is reported here.

\section{METHOD \\ Subjects}

Two experienced male homing pigeons were maintained at $80 \%$ of their ad lib weights. Reinforcements of $3 \mathrm{sec}$ access to Purina Pigeon Chow were sufficient to maintain the birds' weights. Daily experimental sessions were terminated after 30

*We thank Kenneth MacCorquodale for the loan of equipment. This research was partially supported by Grant PS6977 from the T.C.U. Research Foundation. Some of these data were presented at the 1968 Annual Meeting of the American Psychological Association. reinforcements for Bird $N$ and after 18 reinforcements for Bird T. Water and grit were available ad lib in the birds' home cages.

\section{Apparatus}

A three-key Grason-Stadler pigeon box was used. A 10-W houselight illuminated the interior of the box at all times. Electromagnetic programming and recording equipment was located in a sound-shielded room adjacent to the one housing the box.

\section{Procedure}

Baseline training was conducted on a mult chain VI 30-sec VI 30 -sec chain VI 30 -sec VI $30-$ sec schedule for Bird $\mathrm{N}$ and a mult chain VI 2-min VI 2-min chain VI 2-min VI 2-min schedule for Bird T. That is, each component of a two-component multiple schedule was itself a two-link chain schedule. The components of the multiple schedule were presented in a random order, but each of the chain schedules was presented in a fixed order. Only one of the three keys was ever lit at any time, and the position of the lit key did not change during a schedule link. But the position of the lit key did change from link to link on a random basis. The $S^{D_{S}}$ of one chain were horizontal black and white stripes followed by red light projected on the key. The $S^{D_{S}}$ for the other chain were a black outline square on a white background followed by green light on the key. The colored lights were the $S^{D_{S}}$ for the links correlated with reinforcement. The baseline phase lasted for 15 daily sessions for Bird $\mathrm{N}$ and for 20 daily sessions for Bird T.

Immediately after the baseline phase, a DRH procedure was instituted. In this stage of the experiment, a certain number of pecks were required in the last $7.5 \mathrm{sec}$ of each variable interval accompanying the green keylight. The number of responses required varied from day to day and between birds. The response requirements were adjusted so as to increase responding to the green key and prevent pausing. The DRH procedure was in effect for 43 days for Bird $\mathrm{N}$ and for 50 days for Bird $\mathrm{T}$.

Following the DRH procedure, two probe procedures were instituted. In the first probe procedure the schedules of the DRH procedure were maintained. Additionally, one-third of the pecks in the presence of the stripes produced an 0.2 -sec presentation of the green key; one-third of the pecks to the stripes were followed by $0.2 \mathrm{sec}$ of a neutral white key; and the other one-third of the responses produced no probe stimulus. The first probe procedure was in effect for 10 days. The second probe procedure was the same as the first, but the durations of the probe stimuli were increased to $0.3 \mathrm{sec}$, and the procedure had a duration of 8 days. The probe contingencies were then removed, and the DRH procedure restored, for nine sessions for Bird N and 7 sessions for Bird T.

\section{RESULTS}

Figure 1 shows the rates of responding of each bird in each of the four components of the schedule for each session of the entire experiment. It may be seen that a discrimination between the initial components and the terminal components of each of the two chains rapidly developed during the baseline stage: high rates of responding occurred in the terminal (colored key) components of both chains, and low rates of responding occurred in the initial components of both chains. Rates in both terminal components were essentially the same; 

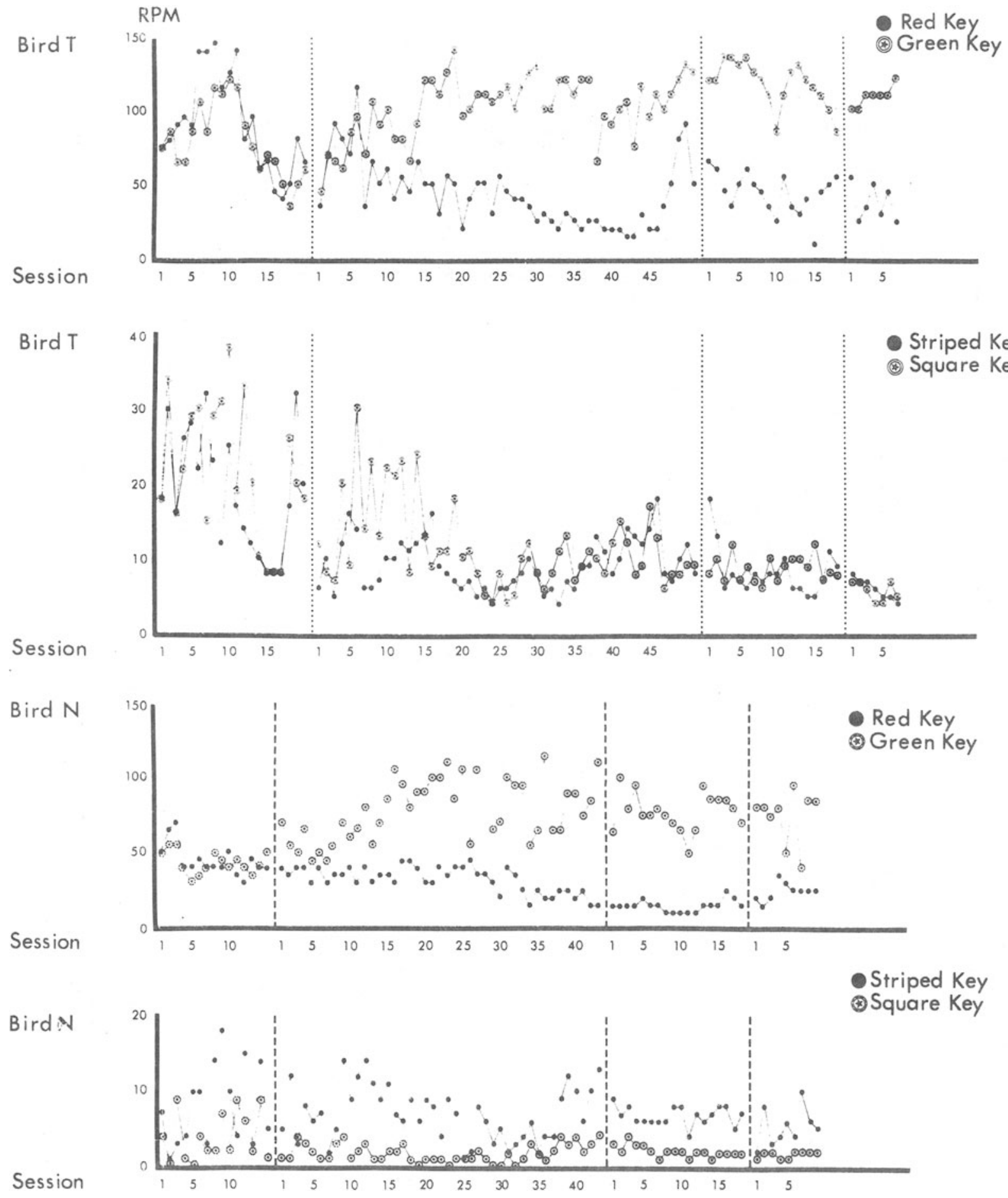

Fig. 1. Rates of responding of each bird in each schedule component on each day of the experiment.

this was also true for the first components of the chains.

During the DRH procedure, response rates in the presence of the green key (DRH contingency) rose during the first 20 sessions to a level approximately twice as great as in the presence of the green light during the baseline phase. Rates in the presence of the green key were maintained at this high level throughout the remainder of the experiment. However, response rates in the presence of the red key declined to approximately half of their baseline values, thus showing negative behavioral contrast. Additionally, response rates in the initial segments of both chains declined below baseline 


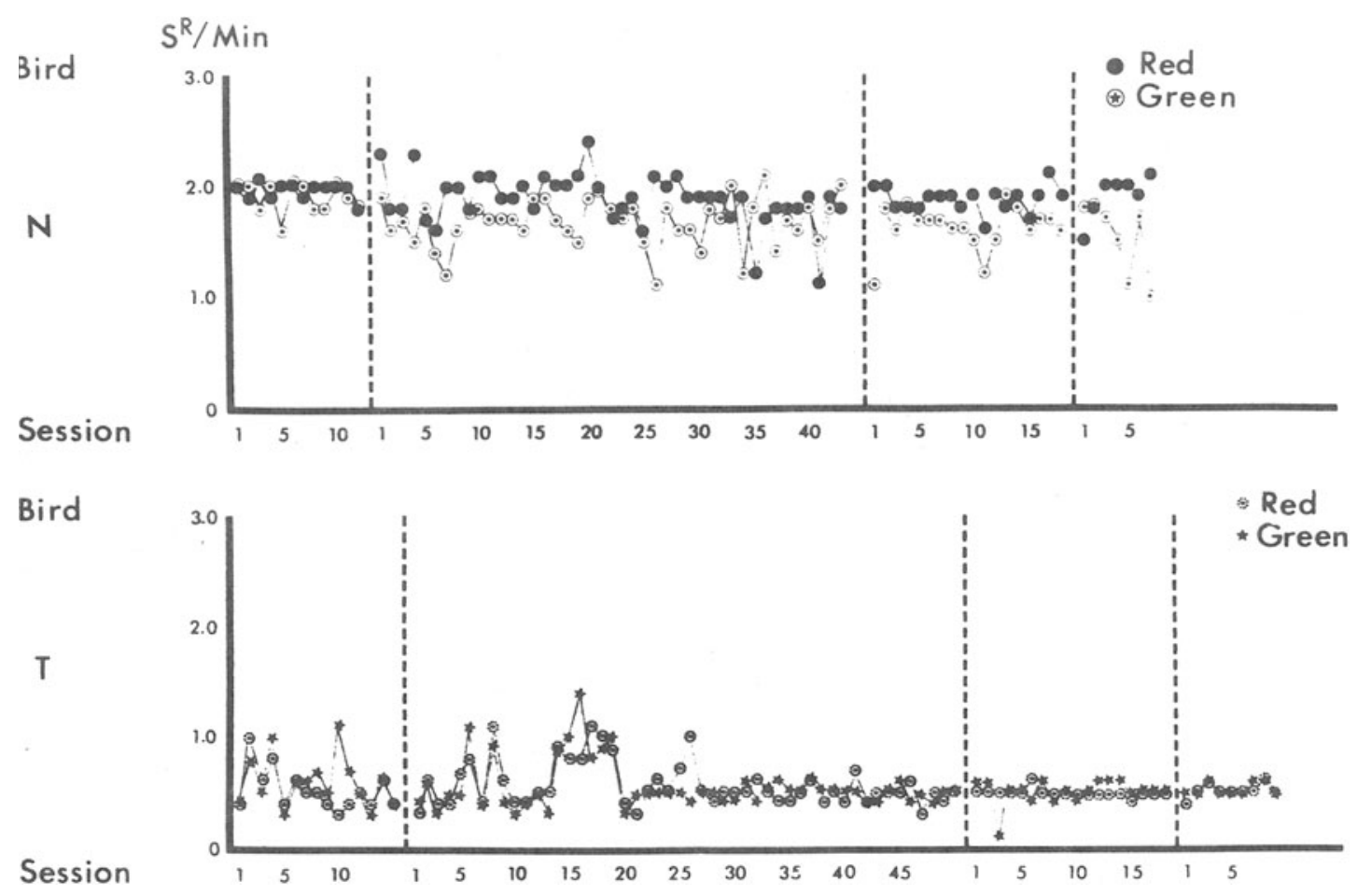

Fig. 2. Rates of reinforcement for each bird on each day of the experiment.

values in the case of Bird $T$, thus further showing negative behavioral contrast.

Figure 1 also shows overall levels of responding in each of the four components during the various probe procedures. Inspection of the response rates during the probe procedures shows that no differences in responding occurred as a result of the probe procedures. The green-key, white-key, and no-stimulus probes had no differential effects, as revealed by a more detailed inspection of the numerical data. It may be seen that the return to the DRH procedure without the probes produced no changes in responding in any of the four links of the schedules.

Figure 2 displays reinforcement rates for both chained components of the multiple schedule for all stages of the experiment for both birds. It may be seen that these rates were fairly constant and equal for each bird.

\section{DISCUSSION}

Reynolds (1961) has emphasized differing temporal rates of reinforcement in the generation of behavioral contrast. In this experiment, the temporal densities of reinforcement in the red and green terminating chains were about equal. If any inequality existed, there was possibly a lower rate of reinforcement in the presence of the green key for Bird N. According to Reynolds, this should have possibly increased responding in the other chain schedules. Therefore, this experiment indicated that negative behavioral contrast will occur without any substantial difference between reinforcement rates in components of a multiple schedule. This corroborates the results of Reynolds \& Limpo (1968) and Mariner \& Thomas (1969).

Terrace (1972) has suggested that various emotional processes are responsible for behavioral contrast. Because of these processes, the stimuli involved in procedures which produce contrast are claimed to acquire excitatory or inhibitory properties with respect to responding. If the green light acquired these properties, the probe procedures should have produced a change in responding. The ineffectiveness of the probe procedures supports Dunham's (1968) and Freeman's (1971) contention that behavioral contrast is not completely explained by accounts of the types discussed above.

\section{REFERENCES}

Dunham, P. J. Contrasted conditions of reinforcement: A selective critique. Psychological Bulletin, 1968, 69, 295-315. Freeman, B. J. Behavioral contrast: Reinforcement frequency or response suppression? Psychological Bulletin, 1971, 75, 347-356.

Mariner, R. W., \& Thomas, D. R. Reinforcement duration and the peak shift in post-discrimination gradients. Journal of the Experimental Analysis of Behavior, 1969, 12, 759-766.

Reynolds, G. S. Behavioral contrast. Journal of the Experimental Analysis of Behavior, 1961, 4, 57-71.

Reynolds, G. S., \& Limpo, A. J. Negative contrast after prolonged discrimination maintenance. Psychonomic Science, $1968,10,323$

Terrace, H. S. Stimulus control. In W. K. Honig (Ed.), Operant behavior: Areas of research and application. New York: Appleton-Century-Crofts, 1966. Pp. 271-344.

Terrace, H. S. By-products of discrimination learning. In G. H. Bower and J. T. Spence (Eds.), The psychology of learning and motivation. Vol. V. New York: Academic Press, 1972. Pp. 195-265.

(Received for publication September 5, 1973.) 